\title{
Impact on Health and Nutrition Outcomes in Sindh Province, Pakistan
}

\author{
Imtiaz Hussain, Sajid Bashir Soofi, Seema Hasan, Nelofer Mehboob, \\ Masawar Hussain, Arjumand Rizvi and Zulfiqar A. Bhutta
}

\begin{abstract}
W e$ independently conducted the impact assessment of the Tawana Pakistan Project (a schoolbased feeding programme to improve the nutritional status of primary school girls in impoverished rural districts of Pakistan). The evaluation was conducted among school-going girls in four districts of Sindh, Pakistan. Pre- and post-intervention data was collected for anthropometric measurements, nutritional status and physical examination. Paired analysis of 1,028 girls (5-12 years) was undertaken using McNemar's test. ${ }^{1}$ Our findings revealed a significant association of the school-based nutrition programme with reductions in the proportion of wasting ( $p<0.0001 ; \mathrm{Cl} 12.2 \%-15.7 \%)$ and underweight ( $\mathrm{p}<0.0001 ; \mathrm{Cl} 9.2 \%-14.5 \%)$ while no association was established for stunting ( $p=0.0817 ; \mathrm{Cl} 0.3 \%-5.5 \%)$. The results support the potential for such programmes in improving the nutritional status of primary school girls in impoverished areas and gains in health and improved growth.
\end{abstract}

\section{Introduction and background}

Many of the children living in low and middleincome countries suffer from undernutrition and have evidence of impaired growth (WHO 2005). Undernutrition, one end of the spectrum of malnutrition, is manifested as stunting, underweight and wasting as well as deficiencies of macro and micro nutrients such as proteins, calories, iron, vitamins, iodine and zinc, etc. (Rosado 1999; Hunt and Quibria 1999).

Micronutrient deficiencies have been labelled the 'hidden hunger' because of the covert influence of the specific deficiencies that may occur even with meals that may be plentiful in macronutrients but lacking in these essential ingredients (Kennedy et al. 2003). Deficiencies of zinc, iron, iodine and vitamin $\mathrm{A}$ are the commonest forms of nutrient deficiencies in Pakistan as in many other developing countries (Hall et al. 2001; IRIN 2003; Liaqat 2004; Nemer et al. 2001), thus posing a significant public health problem by increasing the risk of infections and impairment of physical and mental development (Bundy and Shaeffer 2006). An estimated 60 million children globally or 35-70 per cent of school-going age are affected by iodine deficiency and an estimated
85 million suffer from vitamin A deficiency (Onis 2000).

Asia, especially South Central Asia, has the world's greatest percentage of stunted and highest prevalence of wasted children (Nemer et al. 2001; Onis 2000; Black et al. 2008). About a third of Pakistani children under the age of five are moderate to severely underweight and stunted, and one tenth are wasted (UNICEF 2007); these rates are higher in the rural areas with the exception of wasting, which has been documented to be higher in the urban areas (NNS 2001; HDSA and TMHHDC 2005), possibly among urban slums. Unfortunately there has been little improvement in the nutritional states of Pakistani children over the past 30 years (NNS 2001; Bhutta 2000).

Considering the gloomy situation of child undernutrition (NNS 2001) particularly in girls the Ministry of Women Development conducted a nutrition project called Tawana Pakistan Project (TPP) under the technical assistance of Aga Khan University. The project was designed to provide a meal per day and food supplements for a complete feeding cycle of two years to about 0.5 million girls between the age of 5-12 in low- 


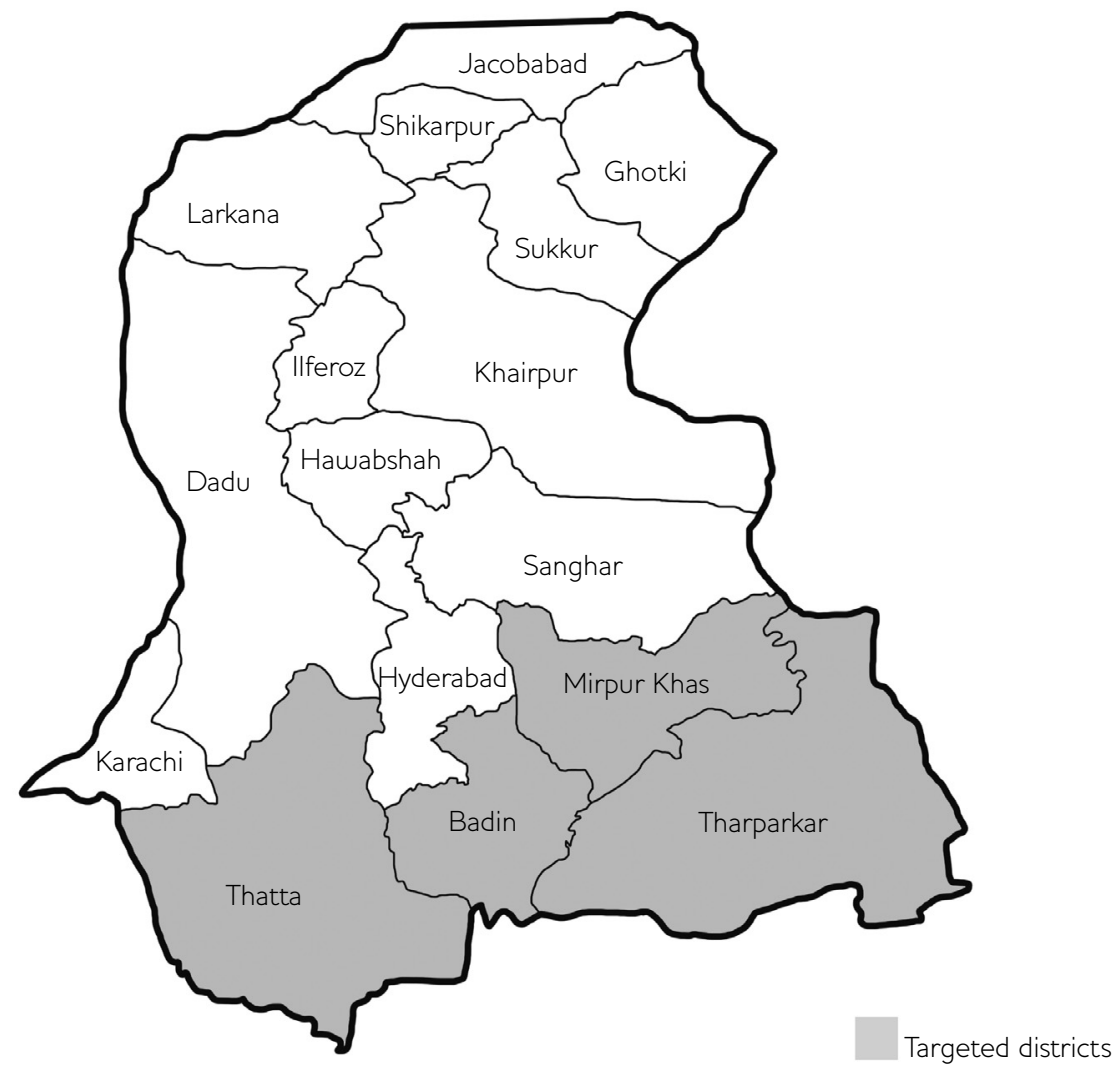

income communities in 29 poverty stricken districts of Pakistan, including two in Gilgit Baltistan and one in Azad Jammu and Kashmir at their schools, with the vision to improve their nutritional status and school attendance.

Notwithstanding an internal monitoring and evaluation system, the Tawana school feeding programme underwent an independent impact assessment and evaluation for health, nutrition and cognitive development through two crosssectional surveys at baseline and endline in Sindh and a nested longitudinal follow-up of a subset, one year following the implementation of the feeding. This independent evaluation is summarised in two assessments, namely the observed impacts on health and nutrition outcomes and the second, a novel assessment of potential impacts on cognitive functions and developmental outcomes. This article summarises the key findings from an assessment of nutrition and health outcomes among recipient primary school girls in rural districts of Sindh, based on the longitudinal cohort data.

\section{Materials and methods Study design}

The study design included two cross-sectional surveys at baseline and endline and a nested longitudinal follow-up of a subset, one year after the implementation of the feeding.

\section{Study population and sample size}

The study population for this assessment was girls aged 6-12 years enrolled in government primary school. This study was carried out in four rural districts (Thatta, Badin, Mirpur Khas and Tharparkar) of Sindh province, Pakistan in 2004-05 (see Figure 1).

The sample size calculations were done using decrease in prevalence of stunting and wasting up to 10 per cent and 20 per cent respectively after implementation of the feeding programme, which is the primary objective of the study using a two-sided test with $\alpha=0.05$ and $\beta=0.20$.

Baseline prevalence of stunting and wasting was 35-42 per cent and 10-16 per cent respectively. Using varying assumptions a range of sample 


\begin{tabular}{|c|c|c|c|c|c|c|c|}
\hline \multicolumn{2}{|c|}{ Nutritional indicators } & \multirow{2}{*}{$\begin{array}{l}\text { Pre-intervention } \\
825 \\
(80.3 \%)\end{array}$} & \multirow{2}{*}{$\begin{array}{l}\text { Post-intervention } \\
971 \\
(94.5 \%)\end{array}$} & \multirow{2}{*}{$\begin{array}{l}\text { OR }(95 \% \mathrm{Cl}) \\
1\end{array}$} & \multirow{2}{*}{$\begin{array}{l}\text { P-value } \\
-\end{array}$} & \multirow{2}{*}{$\begin{array}{l}\text { Change (\%) } \\
-\end{array}$} & \multirow{2}{*}{$\begin{array}{l}\text { Decrease (\%) } \\
-\end{array}$} \\
\hline Wasting & Normal & & & & & & \\
\hline & Wasting & $\begin{array}{l}203 \\
(19.7 \%)\end{array}$ & $\begin{array}{l}57 \\
(5.5 \%)\end{array}$ & $\begin{array}{l}0.24 \\
(0.17,0.32)\end{array}$ & $<0.0001$ & 72.1 & 14.2 \\
\hline \multirow[t]{2}{*}{ Stunting } & Normal & $\begin{array}{l}688 \\
(67.1 \%)\end{array}$ & $\begin{array}{l}661 \\
(64.5 \%)\end{array}$ & 1 & - & - & - \\
\hline & Stunting & $\begin{array}{l}337 \\
(32.9 \%)\end{array}$ & $\begin{array}{l}364 \\
(35.5 \%)\end{array}$ & $\begin{array}{l}1.12 \\
(0.93,1.34)\end{array}$ & 0.20 & -7.9 & -2.6 \\
\hline \multirow[t]{2}{*}{$\begin{array}{l}\text { Under- } \\
\text { weight }\end{array}$} & Normal & $\begin{array}{l}617 \\
(66.1 \%)\end{array}$ & $\begin{array}{l}729 \\
(78.1 \%)\end{array}$ & 1 & - & - & - \\
\hline & $\begin{array}{l}\text { Under- } \\
\text { weight }\end{array}$ & $\begin{array}{l}316 \\
(33.9 \%)\end{array}$ & $\begin{array}{l}204 \\
(21.9 \%)\end{array}$ & $\begin{array}{l}0.54 \\
(0.44,0.67)\end{array}$ & $<0.0001$ & 35.4 & 12.0 \\
\hline
\end{tabular}

Source Authors' own.

size was calculated and the maximum sample size obtained was used, that is, 1,190 for study.

\section{Inclusion and exclusion criteria}

The schools in Sindh province where 'Tawana Project' feeding was continued for one or more years were eligible and others were excluded where feeding had already started at the time of the baseline assessment. The inclusion criteria for selecting the school children was girls, aged 5-12 years, who were residents of the villages and enrolled in the schools at the time of the initiation of the project and who had participated in the baseline assessment.

\section{Pre-testing and training}

A series of pre-tests were conducted, both in rural and urban populations for ensuring the validity of the instruments. The field staff were trained in measuring anthropometry (length/weight) as well as conducting physical examinations and data collection. Anthropometry training of field staff was performed on human subjects of an age group comparable to the study population. Interand intra-rater reliability was used as a measure of quality assurance for the training session.

\section{Operational procedures}

The nutritional assessment was carried out by means of anthropometric measurements and physical examinations. A portable (Seca digital) adult weighing machine was used for the weight measurements. For standardisation purposes, the weighing scales were checked with a $5 \mathrm{~kg}$ weight routinely (every morning) by team leaders. The girls were weighed barefooted and in light clothes on a weighing machine that was placed on a flat, even surface. Wooden stadiometers were used for length measurements. The nutritional anthropometric module of the (Epinut) Epi Info Software, version 6.0 (CDC and Prevention, Atlanta, GA) was used to calculate the $\mathrm{z}$-scores for weight-forage, height-for-age and weight-for-height.

Physical examination for signs of conjunctival pallor, xerophthalmia/Bitot's spots, angular stomatitis, goitre and pluckability of hair (the hair-pull test) was carried out on all targeted girls to assess anaemia and deficiencies of iron, vitamin $A$, vitamin $B$, iodine and zinc, respectively. Age was assessed according to those entered in the school record.

\section{Data management and statistical analysis}

For data entry, data entry screens were developed by using Fox Pro version 6 with necessary range, consistency and logic checks. The data was double entered along with data checks to ensure the quality. Analysis was done using the Statistical Product and Service Solutions software (SPSS Inc. Chicago, IL, USA), version 15. Nutritional status of the girls was examined by converting anthropometric data into standardised scores based on World Health Organization (WHO) standards. A girl was determined to be stunted, wasted or underweight if her height-for-age z-score (HAZ), weight-for- 
Table 2 Micronutrient deficiencies among paired girls (pre- and post-intervention)

\begin{tabular}{llll}
\hline Micronutrient deficiencies & Pre-intervention N (\%) & Post-intervention N (\%) & P-value \\
\hline Hair plucking; Yes & $103(10.0)$ & $88(8.6)$ & $<0.01$ \\
Conjunctival pallor; Yes & $712(69.4)$ & $70(6.8)$ & $<0.01$ \\
Goitre; Yes & $3(0.3)$ & $23(2.2)$ & $<0.01$ \\
Angular stomatitis; Yes & $54(5.3)$ & $17(1.7)$ & $<0.01$ \\
Dental caries; Yes & $315(30.7)$ & $14.3)$ & $<0.01$ \\
\hline
\end{tabular}

Source Authors' own.

height z-score (WHZ) or weight-for-age z-score (WAZ), was less than -2 SD respectively. Both paired and unpaired analysis was done, while this article presents the paired analysis. Group comparison assumed pre- and post-intervention data as independent cohorts examined at two time points. A Chi-square test was used to test the association of feeding with the children's nutritional status. Four combinations of responses for each set of paired data exist:

(i) The child was 'normal' before and after feeding; (ii) The child was 'malnourished' before and after feeding; (iii) The child was 'malnourished' only before feeding; and (iv) The child was 'malnourished' only after feeding. The analysis focused on discordant (yes/no vs. no/yes) pairs only because of the interest in detecting any change in the nutritional status following the feeding programme. Paired bivariate analysis was performed using McNemar's test to compare the observation of discordant pairs by means of a $2 \times 2$ contingency table.

\section{Ethical approval}

This study was approved by the Ethical Review Committee of Aga Khan University, Pakistan.

\section{Results and interpretation}

Two cross-sectional surveys were conducted at baseline and endline and a nested longitudinal follow-up of a subset, one year after the implementation of the school feeding programme, while the baseline survey was conducted in all four provinces of Pakistan targeting 16 districts out of 29 intervention districts. The endline survey was conducted only in Sindh province due to financial constraints. In four districts of Sindh province, a total of 1,441 girls aged 6-12 years participated in the baseline survey and 1,859 in the endline survey for the assessment of health and nutrition indicators.
In order to use each subject in the analysis, two approaches were used to analyse the data; overall group comparison (unpaired) of pre- and postintervention data, and paired bivariate design. Group comparison assumed pre- and postintervention data as independent cohorts examined at two time points. The difference in proportions of discordant pairs was used to quantify the amount of change from the pre- to post-intervention period; the sample size reduced to 1,028 girls when analysed by this method. Findings of paired analysis are presented below with a relevant interpretation.

The analysis of growth indicators of girls aged 6-12 years by pre- and post-intervention is presented in Table 1. The overall growth indicators of girls as measured by their height and weight improved after 12 months of intervention. The baseline prevalence (at preintervention) of wasting was about 19 per cent, stunting was 32.9 per cent and underweight was 33.9 per cent. These decreased by 14.2 per cent, -2.6 per cent and 12.0 per cent from baseline to post-intervention respectively, denoting a rate of change of 72.1 per cent for wasting, -7.9 per cent for stunting, and 34.4 per cent for underweight. The paired observations show no difference in the rate of stunting. Analysis was then done by stratifying wasting, stunting and underweight by the pre and post-intervention status of girls. There was a significant decrease in the percentage of wasted girls $(\mathrm{p}<0.0001$; OR 0.24 $(0.17,0.32))$ whereas the estimates for stunted girls were $(\mathrm{p}<0.20$; OR $1.12(0.93,1.34))$.

Moreover there was a significant decrease in the percentage of underweight girls $(\mathrm{p}<0.0001$;

OR $0.54(0.44,0.67))$.

Table 2 shows the changes in the physical signs of micronutrient deficiencies before and after the 


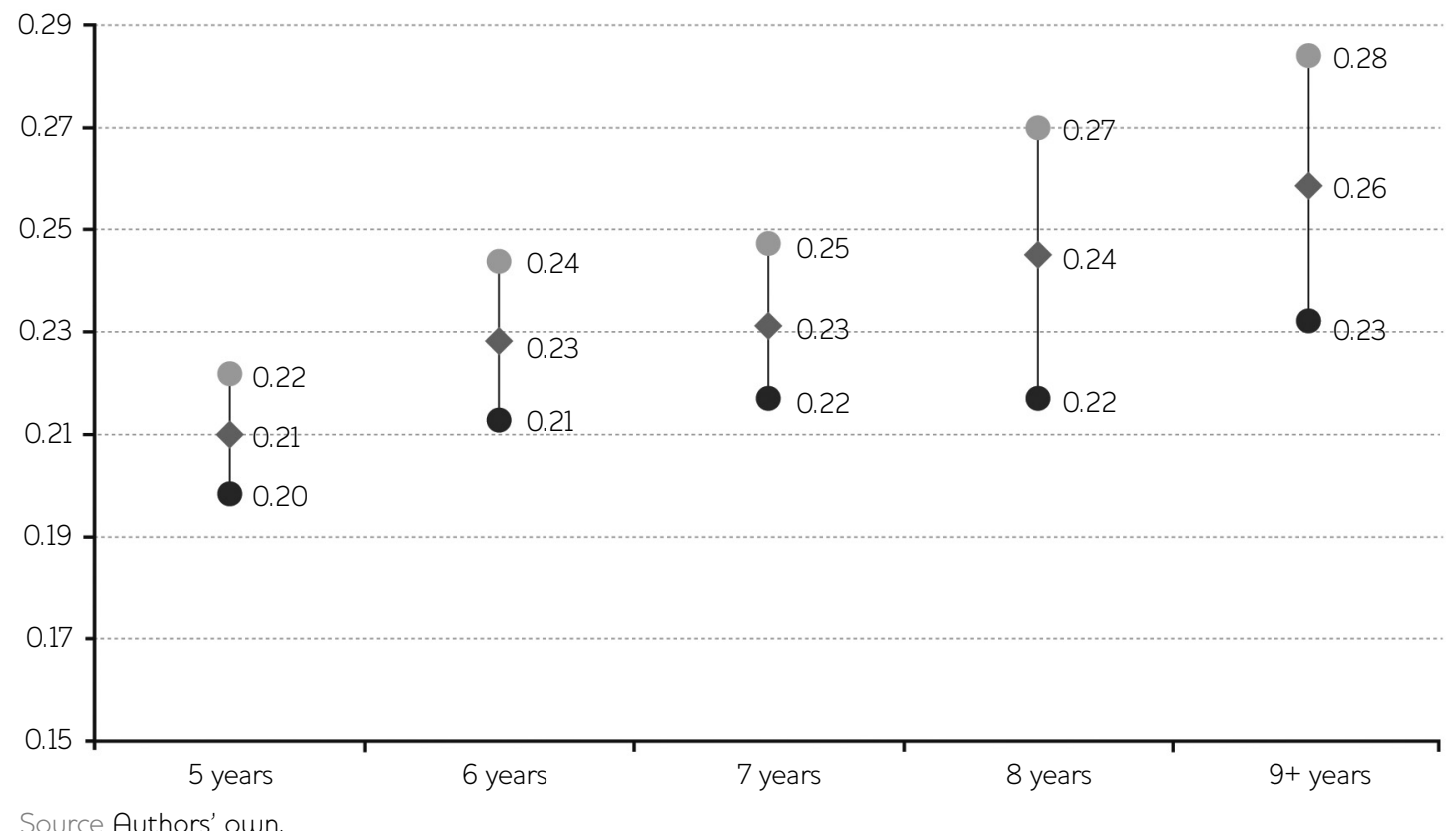

implementation of the feeding programme among the matched groups. Zinc deficiency as measured by the ease of hair plucking, anaemia measured by conjunctival pallor, and vitamin B deficiency measured by angular stomatitis decreased by 1.4 , 62.6 and 3.6 per cent respectively $(\mathrm{p}<0.01)$. There was an increase in the percentage of children who had iodine deficiency, measured by examining and palpating for goitres $(1.9$ per cent, $\mathrm{p}<0.01)$, at the end of the intervention period. Physical examination also showed a decrease in the prevalence of dental caries by 16.4 per cent $(\mathrm{p}<0.01)$ and an improvement in the personal hygiene score $(p=0.001)$.

Figure 2 shows the status of growth indicators by pre- and post-intervention among matched groups. Improvement in rates of wasting and stunting was observed before and after intervention and there is no positive change in rates of stunting.

Figures 3-4: Girls aged 9-12 were grouped together as $9+$ because of a decrease in the number of enrolled girls beyond the age of nine and limitation of the Anthro-plus software. The height and weight of the cohort (Figures 3 and 4) show increasing baseline prevalence in the proportions of nutrition indicators of girls from the age of six to nine years. At the post-intervention assessment of these girls, there is a decrease in the proportion of stunting in all age groups. The decrease was more marked for nine year-olds, and decreased successively for ages eight and seven. Similarly the decrease in the proportion of girls who were underweight decreased successively from nine to seven years. The change in the proportion that was underweight was greater than for those who were stunted.

Figures 5 and 6: Average rate of change was assessed for the cohort of girls, the greatest per month average rate of change in height-by-age was seen for five year-old girls (mean 0.47; CI 0.45-0.49) which steadily decreased for those in the $9+$ age range (mean 0.30; CI 0.28-0.31), while the greatest change in weight gain was seen in $9+$ year-old girls (mean 0.26 ; CI $0.23-0.28$ ) and decreased down to those in the age five years range (mean 0.21 ; CI $0.20-0.22$ ). These changes in height and weight underscore the impact of a balanced diet in improving the height for younger ages, whereas any relationship to weight gain is indifferent to the age of the girls.

\section{Discussion}

This study is one of the few studies undertaken to determine the prevalence of nutritional status of 5-12 year-old girls from impoverished, rural communities of Sindh, Pakistan and the potential 
Figure 3 Status of wasting, stunting and underweight (pre- and post-intervention)

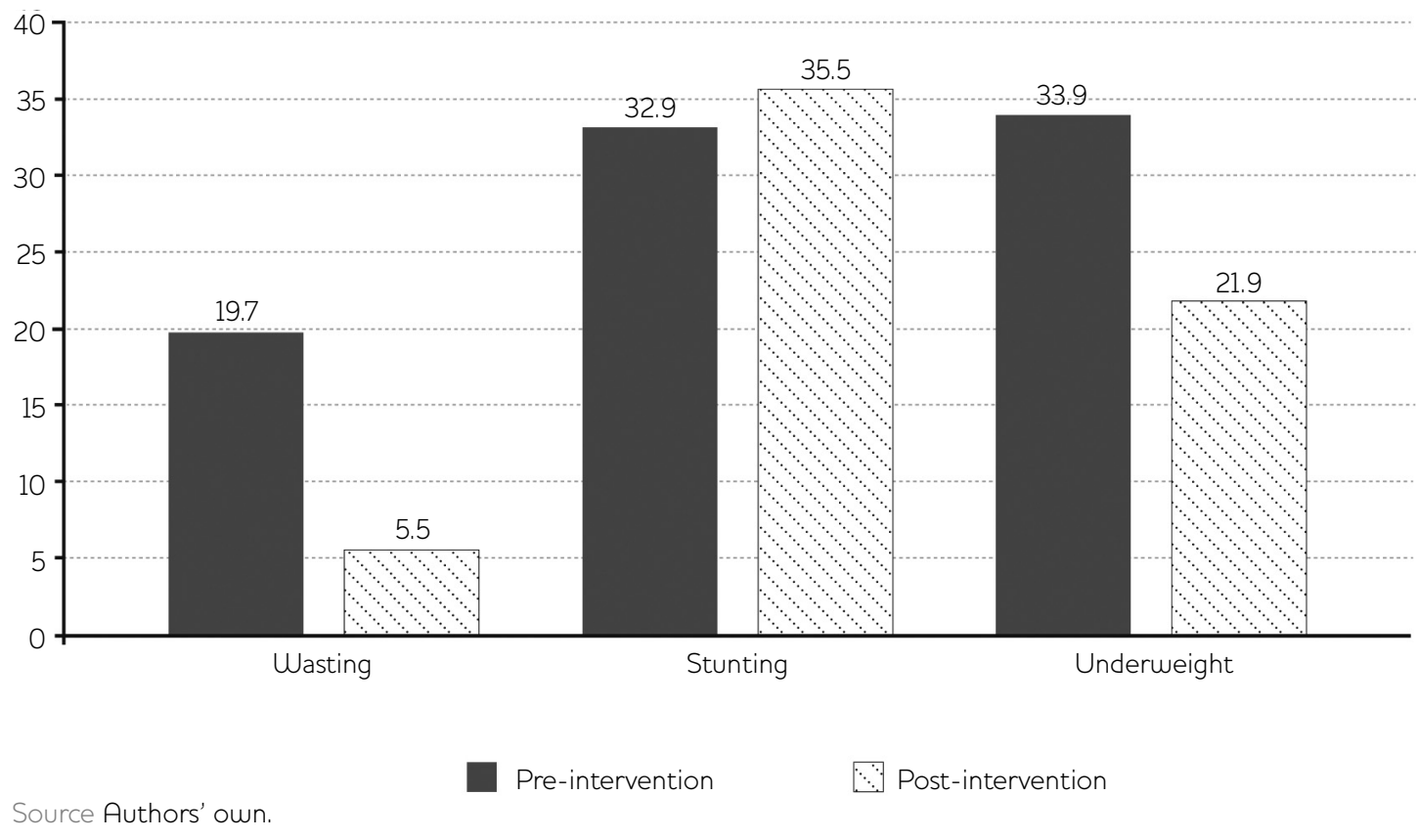

Figure 4 Proportion of wasting among girls by age

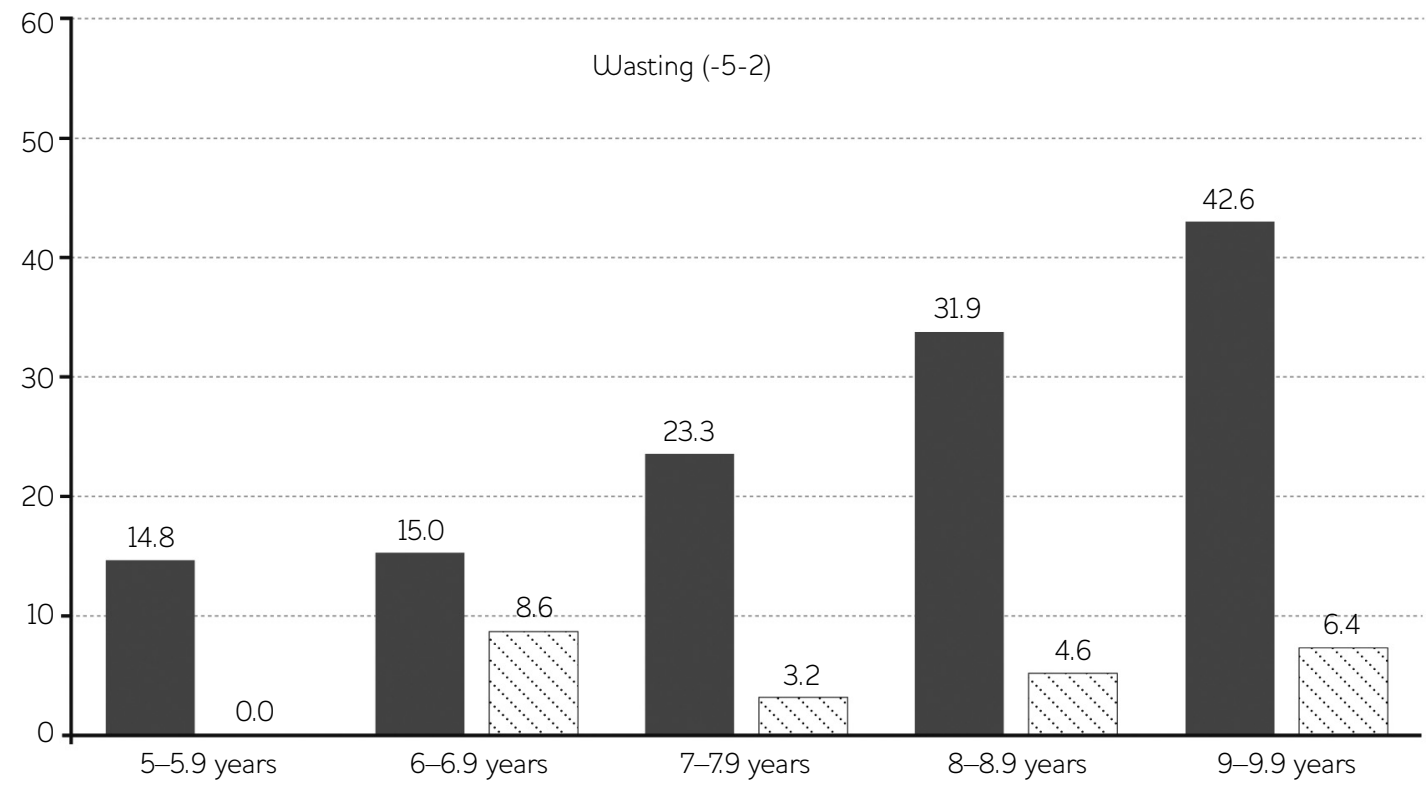

Source Authors' own.

$\operatorname{Pre}(\mathrm{n}=1028)$ 
Figure 5 Proportion of underweight among girls by age

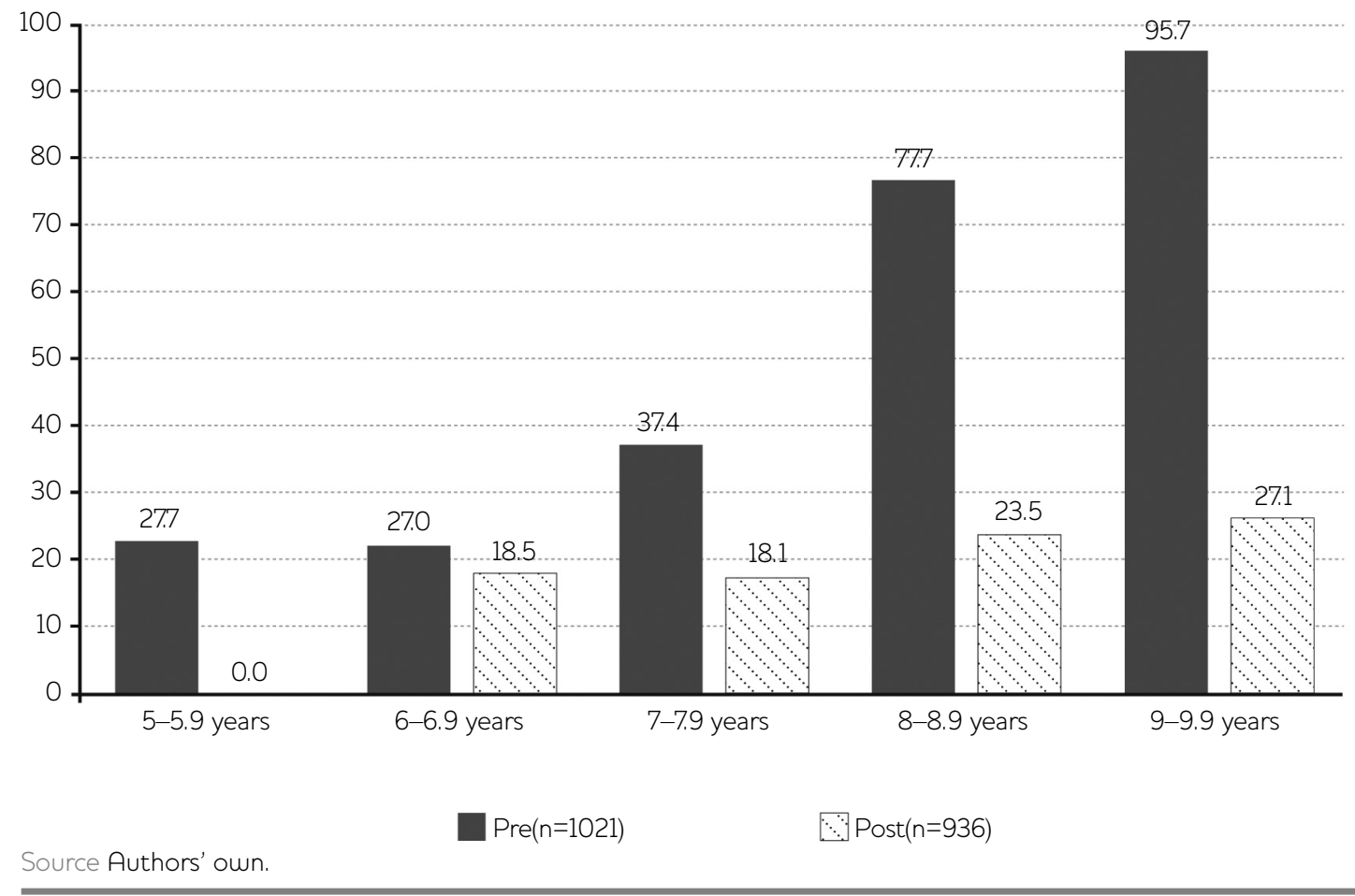

Figure 6 Average change (per month) in height-by-age group

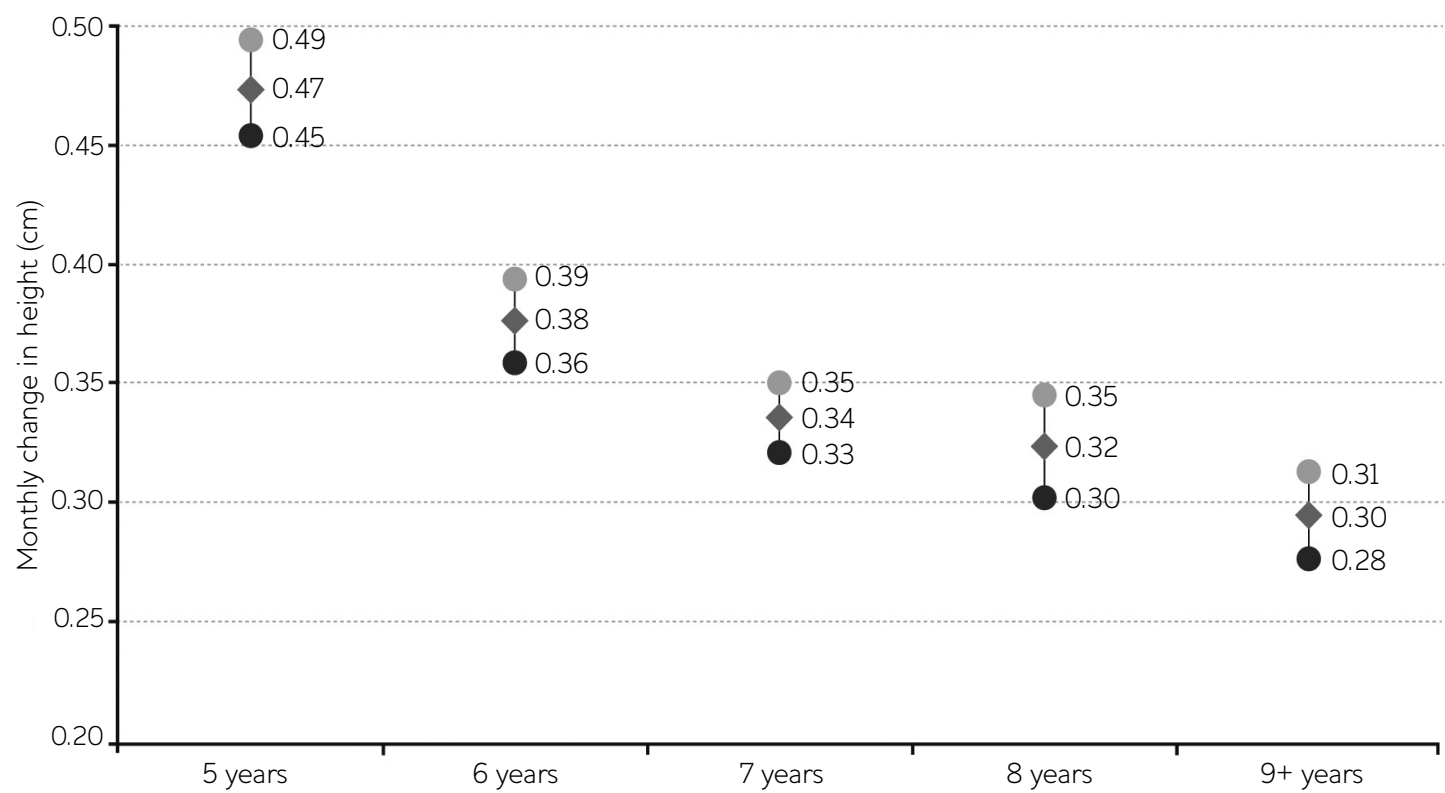

Source Authors' own. 
impact of a defined intervention therein. There are limited studies documenting the height and weight of urban Pakistani children above the age of five, showing the heights and weights below the National Center for Health Statistics (NCHS) centile for 2-18 year-olds (Aziz and Puri 2006) and below the WHO and Food and Agriculture Organization's (FAO) standards for 10-15 year-olds (Gul-e-Raana 2004), while not much difference from the CDC 2000 standards was found for 10-15 year-old affluent children (Hakeem et al. 2004). Indicators for malnutrition among under-five children in Pakistan show that 38 per cent are moderate and severely underweight; 13 per cent are moderate and severely wasted and 37 per cent are moderate and severely stunted (UNICEF 2007).

\section{Among 5-10 year-old urban children from} squatter settlements in Pakistan 30 per cent were found to be underweight, 13 per cent wasted and 35 per cent stunted (Gul-e-Raana 2004). This is quite similar to our baseline assessment of girls aged 5-12 years from four rural districts in Sindh province with a prevalence of 31 per cent for underweight, 12 per cent wasting and 30 per cent stunting. Thus, both these studies show that the rates for these indicators for acute and chronic malnutrition are comparable to figures from under-five children in Pakistan, viz. 38 per cent moderate and severely underweight; 13 per cent moderate and severely wasted and 37 per cent moderate and severely stunted (UNICEF 2007).

The findings of the present study suggest an improvement in the nutritional status of girls 6-12 years of age in the poorest districts of Sindh. The prevalence of wasting (the most acute form of malnutrition) decreased by 14.2 per cent, that is from 19.7 per cent to 5.5 per cent and the prevalence of girls who were underweight also decreased by 12 per cent from 33.9 to 21.9 per cent; this is very consistent with the range reported in the Mahfuz review (Mahfuz 2010) for different school-based interventions. Predictably, there was little impact of the programme on the prevalence of stunting. Further analysis of the impact on nutrition indicators was also performed on girls in the unpaired group by pre- and postintervention, which also shows consistent and significant decrease in the prevalence of undernutrition as evidenced by wasting, underweight and stunting. The main TPP programme also reported similar results of nutrition indicators specifically for wasting and underweight (Badruddin et al. 2008), which suggests that both measures of acute malnutrition are more easily correctible with even short-term nutritional replenishment, regardless of age.

We also established micronutrient deficiencies on the basis of clinical evaluation, although this evaluation does not correlate with the real biochemical evaluation but can provide an indirect indicator for overt micronutrient deficiencies. We found significant improvements in clinical signs of haemoglobin, zinc and vitamin B deficiencies while no difference was found for clinical signs of vitamin A. The large decrease in clinical anaemia between the preand post-intervention phases substantiates the need and potential for measures to reduce irondeficiency anaemia (IDA). IDA is the overwhelming cause of anaemia and related maternal and child disability in most populations and can be corrected by simple, cost-effective means such as supplementation (Bundy and Shaeffer 2006). While vitamin B is not one of the micronutrients currently prioritised for prevention purposes, its deficiency can manifest as cheilosis or angular stomatitis and is easily detectable and provides an early indication of micronutrient deficiencies (Ahmed 2004).

Among the other indicators studied, the significant reduction in the prevalence of dental caries $(<0.01)$ during the course of the evaluation was seen as another manifestation of a reduction in malnutrition rates associated with the TPP feeding programme. Dental caries in childhood and later can be caused by mild to moderate malnutrition in early childhood besides being influenced by behavioural, socioeconomic and other factors (Ahmed 2004; Adelman et al. 2008).

Overall, the impact assessment and evaluation study revealed that the TPP programme achieved a significant improvement in the health and nutrition of girls aged 6-12 years in rural areas of Sindh with a short period of intervention. Our data support the findings of other recent school-feeding intervention studies and global reviews reflected similar kinds of findings, that school feeding programmes are effective in supporting school participation of girls in rural areas with large gender disparities in access to education (Drèze and Kingdon 2001), and are found to bring benefit 
in terms of food consumption as school feeding rations were shared by their older brothers and sisters (Ahmed 2004; Adelman et al. 2008). A global review of school feeding programmes conducted by Gelli (Gelli et al. 2009) suggested that the impact varied with pupils' age, and that household schooling decisions were also affected by the opportunity-costs of education that tend to increase with age and gender (ibid.). A recent systematic review was conducted by Lawson (2012) to assess the effectiveness of school feeding programmes in achieving educational, nutritional and agricultural development goals and revealed modest and mixed effects on nutrition outcomes. Most of the studies included in this review suggest a positive impact of school feeding programmes on wasting and underweight but reported no significant impact on stunting which the authors point out 'is more of a long-run measure of child nutritional status which cannot be influenced in a relatively short period of time' (ibid.).

Although this study provides valuable information on school-based feeding programmes, it is bound to have some limitations. The findings are consistent with recent findings of other school feeding programmes (Gelli et al. 2009; Mahfuz 2010) but we need to emphasise that the attribution of causality is not being attempted in the present study. We lack a control group, and have not run through counter-factual analysis or provided details of how the impact would have occurred. If the TPP consisted of a packaged intervention including feeding, but also health, and health/nutrition awareness-raising in communities, the impact mechanisms would have

\section{Note}

1 http://en.wikipedia.org/wiki/McNemar's_test.

\section{References}

Adelman, S.W.; Gilligan, D.O. and Lehrer, K. (2008) 'How Effective are Food for Education Programs? A Critical Assessment of the Evidence from Developing Countries', Food Policy Review 9, Washington DC: International Food Policy Research Institute

Ahmed, A.U. (2004) Impact of Feeding Children in School: Evidence from Bangladesh, Discussion Paper 138, Washington DC: Food Consumption and Nutrition Division, International Food Policy Research Institute

Aziz, S. and Puri, D.A. (2006) 'Anthropometric Indices of Middle Socio-economic School been complex. We also don't have sufficient information here to be able to gauge if a TPP intervention might be more cost-effective compared to, say, cash transfer. The lack of information on some of these data does not limit the usefulness of the information for future programmes.

The large decrease in signs of anaemia between the pre- and post-intervention phases substantiates the need to direct efforts towards reducing iron deficiency, which is the overwhelming cause of anaemia and related maternal and child debilities in most populations and can be corrected by simple, cost-effective means such as supplementation (Bundy and Shaeffer 2006). While vitamin B is not one of the micronutrients currently prioritised for prevention purposes, its deficiency manifested as cheilosis or angular stomatitis is easily detectable and provides an early indication of micronutrient deficiencies (Moynihan 2005), without the aid of biochemical assays.

In summary, a school-based nutrition programme was associated with improvements in the nutritional status of primary school girls in impoverished areas, demonstrated in this study by an increase in the height and weight and a decrease in anaemia and zinc deficiency. Continuation of such programmes in the poorest sectors of the population, coupled with programmes for boys as well, may foster closer attainment of the Millennium Development Goals of reducing hunger and achieving universal primary education.

Children in Karachi Compared with NCHS Standards - A Pilot Study', Journal of Pakistan Medical Association 56.6: 264-7

Badruddin, S.H.; Agha, A.; Peermohamed, H.; Rafique, G.; Khan, K.S. and Pappas, G. (2008) 'Tawana Project - School Nutrition Program in Pakistan - Its Success, Bottlenecks and Lessons Learned', Asia Pacific Journal of Clinical Nutrition 17.S1: 357-60

Bhutta, Z.A. (2000) 'Why has so Little Changed in Maternal and Child Health in South Asia?', British Medical Journal 321: 809-12, www.bmj.com/cgi/content/full/32 1/7264/809 (accessed 14 February 2013) 
Black, R.E.; Allen, L.H. and Bhutta, Z.A. (2008) 'Maternal and Child Undernutrition: Global and Regional Exposures and Health Consequences', Maternal and Child Undernutrition Series 1, The Lancet 371.9608: 243-60

Bundy, D.A.P. and Shaeffer, S. (2006) 'School Based Health and Nutrition Programs', Chapter 58 in D.T. Jamison, J.G. Breman, A.R. Measham et al. (eds), Disease Control Priorities in Developing Countries, Washington DC: World Bank: 1091-107

Drèze and Kingdon (2001) 'School Participation in Rural India', Review of Development Economics 5.1: 24

Gelli, A.; Al-Shaiba, N. and Espejo, F. (2009) 'The Costs and Cost-efficiency of Providing Food through Schools in Areas of High Food Insecurity', Food and Nutrition Bulletin 30.1: 68-75

Gul-e-Raana (2004) 'Nutritional Status of School-going Girls of Peshawar - NWFP', Sarhad Journal of Agriculture 20.3: 465-7

Hakeem, R.; Shaikh, A.H. and Asar, F. (2004) 'Assessment of Linear Growth of Affluent Urban Pakistani Adolescents According to CDC 2000 References', Annals of Human Biology 31.3: 282-91

Hall, A. et al. (2001) 'Anaemia in Schoolchildren in Eight Countries in Africa and Asia', Public Health Nutrition 4.3: 749-56

HDSA (Human Development in South Asia) and The Mahbubul Haq Human Development Centre (2005) Human Development in South Asia 2004: The Health Challenge, Oxford and New York: Oxford University Press

Hunt, J. and Quibria, M.G. (1999) 'Preface', Asian Development Review, Studies of Asian and Pacific Economic Issues 17.1/2: 132-67

IRIN (2003) Pakistan: National Nutrition Survey Reveals Disturbing Trends, 18 November, United Nations Office for the Coordination of Humanitarian Affairs, www.irinnews.org/report.aspx?reportid $=21367$ (accessed 4 January 2008)

Kennedy, G.; Nantel, G. and Shetty, P. (2003) 'The Scourge of "Hidden Hunger": Global Dimensions of Micronutrient Deficiencies',
Food, Nutrition and Agriculture 32: 8-16

Lawson, Ty (2012) Impact of School Feeding Programs on Educational, Nutritional, and Agricultural Development Goals: A Systematic Review of Literature, Master's Plan B Paper, Michigan State University

Liaqat, P. (2004) An Overview of Food, Nutrition and Health in Islamic Republic of Pakistan, Intercountry Technical Consultation on National Food Based Dietary Guidelines, 6-9 December Mahfuz, Mustafa (2010) 'Impact of School Feeding Programmes on Growth of Children A Systematic Review', in Bhutta, Z.A. (ed.), Nutrition Interventions for Maternal and Child Health and Survival, Pakistan: OUP

Moynihan, P.J. (2005) 'The Role of Diet and Nutrition in the Etiology and Prevention of Oral Diseases', Bulletin of the World Health Organization 83.9: 694-99

Nemer, L.; Gelband, H. and Jha, P. (2001) The Evidence Base for Interventions to Reduce Malnutrition in Children Under Five and School-age Children in Low and Middle-income Countries, CMH Working Paper Series Paper WG5:11, Commission on Macroeconomics and Health NNS (2001) National Nutrition Survey of Pakistan, Islamabad: Government of Pakistan, Pakistan Institute of Development Economics and UNICEF

Onis, M. de (2000) 'Is Malnutrition Declining? An Analysis of Changes in Levels of Child Malnutrition since 1980', special theme child mortality, Bulletin of the World Health Organization 78: 1222-33

Rosado, J.L. (1999) 'Separate and Joint Effects of Micronutrient Deficiencies on Linear Growth', Journal of Nutrition 129: 531-3

UNICEF (2007) The State of the World's Children. Statistical Tables 2007, Table 2 Nutrition, United Nations International Children's Education Fund

WHO (2005) 'Nutrition in Adolescence - Issues and Challenges for the Health Sector: Issues in Adolescent Health and Development', Discussion Papers on Adolescence, Geneva: World Health Organization 